\title{
Modeling of proportions and prediction of properties of macadam and sand mixes stabilized with mineral binders with the ant additive
}

\author{
Vakhtang Matua ${ }^{1}$, Sergey Sizonets ${ }^{1 *}$, and Dmitry Stroev ${ }^{1}$ \\ ${ }^{1}$ Don State Technical University, department of highways, 344002 Rostov-on-Don, Russia
}

\begin{abstract}
Optimization of the proportion and the properties of stabilized macadam and sand mixes (MSM) with introduction of the ANT additive was carried out by means of the mathematical designing of the experiment. This method allows a rather full and comprehensive assessment of the effect of the components on the properties of stabilized macadam and sand mixes (MSM), obtaining of the mathematical model of the process in graphic form, and obtaining of the theoretical model of assessment and prediction of the physical-mechanical and performance properties of the materials under study. At the first stage of the research percentages of a mineral binder, water and an additive were selected and the effect of the variability factor of these components on the mix's physical-mechanical properties was studied. The following factors were selected as variates: $\mathrm{X}_{1}$ standing for quantity of water, $\% ; \mathrm{X}_{2}$ standing for the content of sulfateresistant portland cement grade $500, \% ; X_{3}$ standing for the content of the ANT ionic stabilizer being essentially a water-soluble active organomineral additive containing amphoteric surfactants and microelements, $\%$. The experimental design and the levels of the factors' variability were specified on the basis of the test results. The principal factor exerting influence on the strength property of stabilized macadam and sand mixes is application of the ANT $\mathrm{X}_{3}$ ionic stabilizer.
\end{abstract}

\section{Introduction}

Over recent years the approach to experimental statistical study and optimization of complex multicomponent systems has drastically changed. Methods of mathematical designing of the experiment are successfully applied in various fields of scientific and engineering research. Extensive application thereof significantly improves the efficiency of the studies and manifests their versatility and applicability in most of the construction materials research.

Optimization of the proportion and the properties of stabilized macadam and sand mixes (MSM) with introduction of the ANT additive was carried out by means of mathematical

\footnotetext{
* Corresponding author: sizonez@rambler.ru
} 
designing of the experiment $[1,2]$. Mathematical designing of an experiment is a procedure of selection of the number and the conditions of epy design of the experiments necessary and sufficient for solving of this problem with the required accuracy, the methods of mathematical analysis of the results thereof and the decision-making. In designing of experiments the experiment is thought of as a target of research and optimization. Here the optimal management of the experiment is done. Depending on the available information about the system under study, the research strategy is changed with selection of the optimal strategy for each stage. This method allows a rather full and comprehensive assessment of the effect of the components on the properties of stabilized macadam and sand mixes (MSM), obtaining of the mathematical model of the process in graphic form, and obtaining of the theoretical model of assessment and prediction of the physical-mechanical and performance properties of the materials under study.

In the modern construction field, both abroad and in our country, as a rule a considerable part of stabilized mixes is produced with application of various chemical additives which in small volume allow controlling of the technological process to a significant degree and obtaining of the mixes with the required physical chemical properties. Thanks to the development of the chemical, petrochemical, cellulose and paper, fat-and-oil and other industries, the range of additives has considerably expanded.

According to the reviews of the foreign technical magazines in Germany, Great Britain, Belgium, Hungary, Japan, and etc. [3-6, and etc.], application of additives allows making of the mixes which almost completely satisfy construction and technology requirements.

In Switzerland the Consolid 444 additive was invented, which enhances strength of the mineral binder-stabilized materials approximately by 15 to $20 \%$ [7].

In the Netherland the RoadCem additive was invented, which improves strength approximately by 10 to $15 \%$ [8]. The RoadCem additive shows good performance if cement-based. Application of the RoadCem modifies the crystallization process. The bonding mechanism changes from "gluing" to "weaving". It allows using of any cohesionless materials for construction of the road bed [9]. The studies have shown [10-14], that cement-based cohesionless materials with the RoadCem additive have enhanced mechanical properties.

In the USA the M10+50 and LBS additives were invented, which are essentially acrylic copolymer-based liquid binding polymer impregnating compounds. This emulsion was developed to improve physical-mechanical properties of cohesionless materials applied in base courses. The studies, carried out in the USA, have shown that polymer emulsions do ensure a considerable gain in strength even under the conditions of extreme humidity [15].

In Russia the ANT additive was invented, which is essentially a water-soluble active organo-mineral additive containing amphoteric surfactants and microelements [16]. This additive creates stable crystallizing and coagulative bonds, and it is recommended to apply it with the mineral binder. In such a case the additive boosts physical-mechanical characteristics and ensures decrease in the mineral binder flow [17]. The studies [18, 19] have shown that with introduction of the ANT stabilizer the compression strength of the stabilized material composition increases to $23 \%$. The tensile strength in bending also rises to $25 \%$, thus manifesting the increase in the strain capacity of the obtained material and therefore reduction of crack formation.

Based on the above stated, it was established that introduction of the ANT additive in stabilized macadam and sand mixes ensures the best physical-mechanical characteristics.

Thus, one can conclude as follows:

- application of the ANT additive is one of the practicable ways of technology improvement and obtaining of stabilized mixes with desired properties;

- feasibility of application of the ANT additive should be supported by modeling of the proportions and prediction of the properties of the stabilized mixes. 


\section{Methods}

The vast majority of the phenomena under study should be thought of as the complex systems, depending on the great number of independent variables. One part of them can exert significant influence on the output parameter under study, the other part insignificant one. Since the degree of effect of certain variables is usually a priori unknown, at the first stages of study of complex systems the research program should include all the variables suspected to be capable of having an effect on the output parameter. That is why implementation of the research and optimization of the complex systems by the methods of mathematical designing of experiments consisted of a number of stages. At each stage the location of experimental points optimal for this stage was selected.

At the first stage of the research percentages of a mineral binder, water and an additive were selected, and effect of the variability factor of these components on the physicalmechanical properties of the mix was studied. The following factors were selected as variates: $\mathrm{X}_{1}$ standing for quantity of water, $\% ; \mathrm{X}_{2}$ standing for the content of sulfateresistant portland cement grade 500, SRPC 500-D20, \%; $X_{3}$ standing for the content of the ANT ionic stabilizer being essentially a water-soluble active organo-mineral additive containing amphoteric surfactants and microelements [16] \%. The experimental design and the levels of the factors' variability were specified on the basis of the test results. The factors under study and their variability intervals are set forth in table 1. Samples of the mixes under study were made in accordance with GOST 23558-94. For preparation and testing of the samples of the mixes with the coarseness of grain maximum $20 \mathrm{~mm}$ the SoyuzdorNII big standard compaction measuring device (SCMD) was used. Initially the sulfate-resistant portland cement SRPC 500-D20 was introduced to the mineral material mix with optimal grain size composition. Thereafter the mix was homogeneously stirred until a homogenous mix was obtained. Then the aquatic solution of chemical additives was introduced to the mix due to which the mix acquired the optimum water content established during the experiment. Afterwards the mix was poured into the mould of the SoyuzdorNII big measuring device in three steps, poking each layer 25 times with the metallic rod with $12 \mathrm{~mm}$ diameter. After the whole mix was cast, it was compacted in one step by 120 strokes of a balance weight of $2.5 \mathrm{~kg}$ falling from the height of $30 \mathrm{~cm}$. Then the samples were removed from the SoyuzdorNII measuring device and stored under the natural thermal and humidity conditions during the required period of time prior to testing (28 days). Before testing the samples underwent capillary water saturation within 72 hours. Capillary water saturation of the samples was done through the layer of damp sand. Then the samples' compression strength and tensile strength in bending were measured according to GOST 10180 .

Table 1. Factors under study and variability intervals in the experimental design

\begin{tabular}{|l|c|c|c|c|}
\hline \multirow{2}{*}{ Characteristics } & \multirow{2}{*}{ Code value } & \multicolumn{3}{|c|}{ Factors under study } \\
\cline { 3 - 5 } & & $X_{1}$ & $\begin{array}{c}X_{2} \\
\text { Water, \% } \\
\text { Portland } \\
\text { cement, \% }\end{array}$ & $\begin{array}{c}X_{3} \\
\text { Additive } \\
\text { (ANT), \% }\end{array}$ \\
\hline Basic level $\left(X_{0 i}\right)$ & 0 & 3.5 & 4.0 & 0.3 \\
\hline Variability interval $\left(\Delta_{i}\right)$ & $\mathrm{X}$ & 1.0 & 1.0 & 0.3 \\
\hline Higher level $\left(X_{i} \max \right)$ & $\mathrm{X}_{\mathrm{i}}=+1$ & 4.5 & 5.0 & 0.6 \\
\hline Lower level $\left(X_{i} \min \right)$ & $\mathrm{X}_{\mathrm{i}}=-1$ & 2.5 & 3.0 & 0.0 \\
\hline
\end{tabular}


At the second stage the following values were studied: compression strength $\left(\mathrm{R}_{\text {compr }}\right.$, $\mathrm{MPa}), \mathrm{Y}_{1}$; tensile strength in bending ( $\left.\mathrm{R}_{\text {bend }}, \mathrm{MPa}\right), \mathrm{Y}_{2}$.

In the theory of experimental design these values $\mathrm{Y}_{\mathrm{i}}$ are usually called response functions.

The response function comprises a non-random and a random component. Many quality indices of automated information processing systems have random nature. It requires repetitive experiments under the same conditions with the view to obtain statistically stable results, while the obtained indices' values should be consistent, efficient, unbiased and sufficient. Estimation of typical indices is made by means of averaging of the results of observations. That is why with a fairly large number of observations it may be considered that the random component is normally distributed with zero mathematical expectation, which enables obtaining of the unbiased estimator of the response function's mathematical expectation in a specific design point.

The number of degrees of freedom is calculated by the formula: $f 1=m-n-1$,

where $\mathrm{m}$ stands for the number of tests (is 17);

$\mathrm{n}$ stands for the number of regression coefficients (is 10);

$\mathrm{fl}=\mathrm{m}-\mathrm{n}-1=17-10-1=6$

The Student's coefficient is taken from the tables, for example, those in the V.A. Voznesensky's textbook [1], which, depending on the exceedance probability $(0.05)$ and the number of degrees of freedom $(\mathrm{fl}=6)$, constitutes 2.447 .

The experimental design and natural values of the factors under study in each design point are set forth in Table 2 .

Table 2. Experimental design and natural values of variables

\begin{tabular}{|c|c|c|c|c|c|c|}
\hline \multirow{2}{*}{$\begin{array}{c}\text { Design } \\
\text { number }\end{array}$} & \multicolumn{3}{|c|}{ Experimental design } & \multicolumn{3}{c|}{ Natural values of variables } \\
\cline { 2 - 7 } & $X_{1}$ & $X_{2}$ & $X_{3}$ & $\begin{array}{c}X_{1} \\
\text { Water, \% }\end{array}$ & $\begin{array}{c}X_{2} \\
\text { Portland } \\
\text { cement, \% }\end{array}$ & $\begin{array}{c}X_{3} \\
\text { Additive } \\
\text { (ANT),\% }\end{array}$ \\
\hline 1 & +1 & -1 & -1 & 3.5 & 2.0 & 0.0 \\
\hline 2 & +1 & -1 & +1 & 3.5 & 2.0 & 0.6 \\
\hline 3 & -1 & -1 & +1 & 1.5 & 2.0 & 0.6 \\
\hline 4 & -1 & -1 & -1 & 1.5 & 2.0 & 0.0 \\
\hline 5 & 0 & -1 & 0 & 2.5 & 2.0 & 0.3 \\
\hline 6 & 0 & 0 & -1 & 2.5 & 3.0 & 0.0 \\
\hline 7 & -1 & 0 & 0 & 1.5 & 3.0 & 0.3 \\
\hline 8 & 0 & 0 & +1 & 2.5 & 3.0 & 0.6 \\
\hline 9 & +1 & 0 & 0 & 3.5 & 3.0 & 0.3 \\
\hline 10 & 0 & 0 & 0 & 2.5 & 3.0 & 0.3 \\
\hline 11 & +1 & +1 & -1 & 3.5 & 4.0 & 0.0 \\
\hline 12 & +1 & +1 & +1 & 3.5 & 4.0 & 0.6 \\
\hline 13 & -1 & +1 & +1 & 1.5 & 4.0 & 0.6 \\
\hline 14 & -1 & +1 & -1 & 1.5 & 4.0 & 0.0 \\
\hline 15 & 0 & +1 & 0 & 2.5 & 4.0 & 0.3 \\
\hline 16 & 0 & 0 & 0 & 2.5 & 3.0 & 0.3 \\
\hline 17 & 0 & 0 & 0 & 2.5 & 3.0 & 0.3 \\
\hline
\end{tabular}

\section{Results and Discussion}

Average values of experimental data for each design point of the physical-mechanical indices of stabilized macadam and sand mixes (MSM) under study are set forth in Table 3. 
Table 3. Results of testing of engineering samples and calculated values of properties

\begin{tabular}{|c|c|c|}
\hline \multirow{2}{*}{$\begin{array}{c}\text { Experime } \\
\text { nt No. }\end{array}$} & \multicolumn{2}{|c|}{ Y property under study } \\
\cline { 2 - 3 } & Compression strength at 20 ${ }^{\circ}$ C, MPa & Tensile strength in bending, MPa \\
\hline 1 & $3.00 / 3.019$ & $0.47 / 0.478$ \\
\hline 2 & $2.80 / 2.808$ & $0.43 / 0.437$ \\
\hline 3 & $2.90 / 2.902$ & $0.45 / 0.453$ \\
\hline 4 & $3.09 / 3.078$ & $0.50 / 0.509$ \\
\hline 5 & $3.50 / 3.490$ & $0.62 / 0.623$ \\
\hline 6 & $4.01 / 4.011$ & $0.80 / 0.801$ \\
\hline 7 & $4.55 / 4.558$ & $0.85 / 0.855$ \\
\hline 8 & $4.25 / 4.258$ & $0.84 / 0.846$ \\
\hline 9 & $4.73 / 4.731$ & $0.86 / 0.861$ \\
\hline 10 & $4.77 / 4.766$ & $0.88 / 0.886$ \\
\hline 11 & $4.95 / 4.959$ & $0.87 / 0.879$ \\
\hline 12 & $4.04 / 4.061$ & $0.80 / 0.801$ \\
\hline 13 & $4.15 / 4.158$ & $0.81 / 0.818$ \\
\hline 14 & $4.85 / 4.861$ & $0.87 / 0.871$ \\
\hline 15 & $5.24 / 5.249$ & $1.23 / 1.238$ \\
\hline 16 & $4.77 / 4.766$ & $0.88 / 0.886$ \\
\hline 17 & $4.77 / 4.766$ & $0.88 / 0.886$ \\
\hline
\end{tabular}

Note: above the line is experimental result, below the line is theoretical result.

Having extracted all the existing factors and interactions and having estimated the regression coefficients corresponding to them, adequacy of description of experimental results was verified. Dependence between the variables under study and the physicalmechanical properties of binders was established with the help of the regression equation:

$$
Y=b_{0}+b_{1} X_{1}+b_{2} X_{1}^{2}+b_{3} X_{2}+b_{4} X_{2}^{2}+b_{5} X_{3}+b_{6} X_{3}^{2}+b_{7} X_{1} X_{2}+b_{8} X_{1} X_{3}+b_{9} X_{2} X_{3}
$$

Numerical values of regression coefficients of second-order polynomial models are set forth in Table 4.

Table 4. Regression coefficients of polynomial models of properties of stabilized macadam and sand mixes (MSM)

\begin{tabular}{|c|c|c|}
\hline \multirow{2}{*}{$\begin{array}{l}\text { Regression } \\
\text { coefficients }\end{array}$} & \multicolumn{2}{|c|}{ Response function } \\
\cline { 2 - 3 } & $\mathbf{Y}_{\mathbf{1}}\left(\mathbf{R}_{\text {compr }}\right)$ & $\mathbf{Y}_{\mathbf{2}}\left(\mathbf{R}_{\text {bend }} \mathbf{)}\right.$ \\
\hline $\mathrm{b}_{0}$ & 2.798003 & 3.766890 \\
\hline $\mathrm{b}_{1}$ & -0.124000 & 0.196556 \\
\hline $\mathrm{B}_{2}$ & 0.566001 & -0.62066 \\
\hline $\mathrm{B}_{3}$ & 0.146667 & 0.218333 \\
\hline $\mathrm{B}_{4}$ & -0.116997 & -0.095058 \\
\hline $\mathrm{B}_{5}$ & 0.081998 & -0.011886 \\
\hline $\mathrm{B}_{6}$ & 0.091995 & -0.896891 \\
\hline $\mathrm{B}_{7}$ & 0.039999 & -0.087223 \\
\hline $\mathrm{B}_{8}$ & 0.004999 & 0.003611 \\
\hline $\mathrm{B}_{9}$ & 0.005000 & 0.006250 \\
\hline
\end{tabular}

The obtained models represent a sufficient description of the system behavior, since the necessary condition of $\mathrm{F}_{\text {calc }}<\mathrm{F}_{\text {table }}$ is met. Calculated values of the Fisher's ratio test are set forth in Table 5. The Fisher's ratio test is applied for testing of equality of variances of two samples. It is referred to dispersion criteria.

The obtained calculated value is compared with the table value specified in reference literature. The table is set up as follows. Columns are associated with the certain number of degrees of freedom for numerator $\mathrm{f}_{1}$, and rows - for denominator $\mathrm{f}_{2}$. At the intersection of 
the appropriate row and column the critical values of the F-criterion are put. As a rule, in engineering problems the confidence level 0.05 is applied. If the estimated value of the Fcriterion does not exceed the table one, then the model may be deemed adequate with appropriate confidence probability (no less than $95 \%$ ). If the table value is exceeded, it is necessary to reject this model.

Table 5. Values of the Fisher's ratio test of mathematical models

\begin{tabular}{|c|l|c|c|}
\hline $\begin{array}{c}\text { No of } \\
\text { pos. }\end{array}$ & \multicolumn{1}{|c|}{ Model type } & Values $\mathbf{F}_{\text {table }}$ & $\begin{array}{c}\text { Values } \\
\mathbf{F}_{\text {calc }}\end{array}$ \\
\hline 1 & Compression strength $\left(\mathrm{Y}_{1}\right)$ & 1.635 & 1.205 \\
\hline 2 & Tensile strength in bending $\left(\mathrm{Y}_{2}\right)$ & 0.872 & 0.457 \\
\hline
\end{tabular}

In Figure 1 to 2 isosurfaces of principal physical-mechanical properties of stabilized macadam and sand mixes (MSM) are shown.

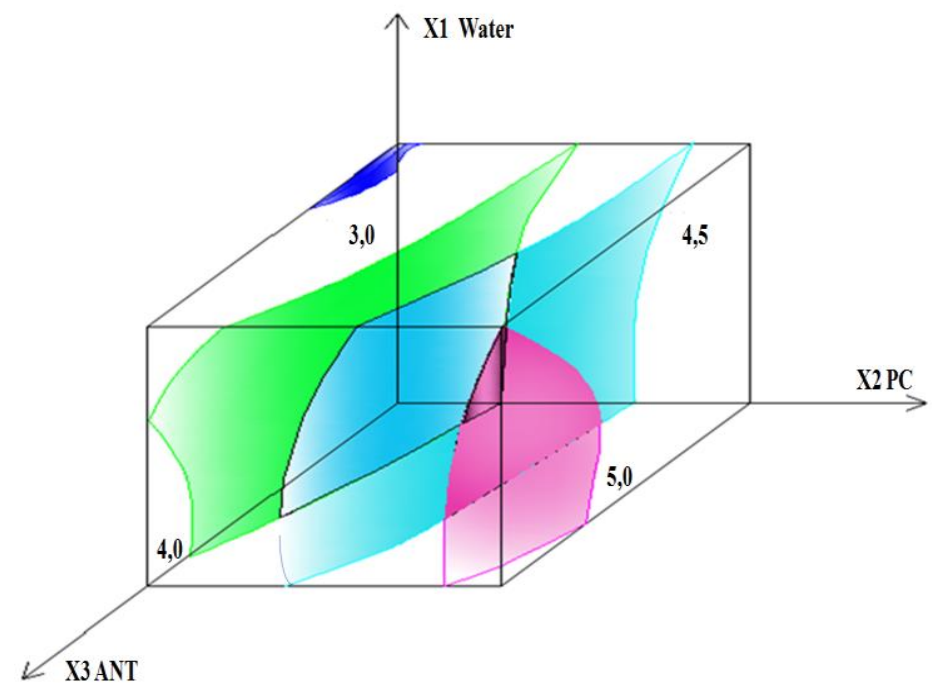

Fig. 1. Isosurfaces of compression strength

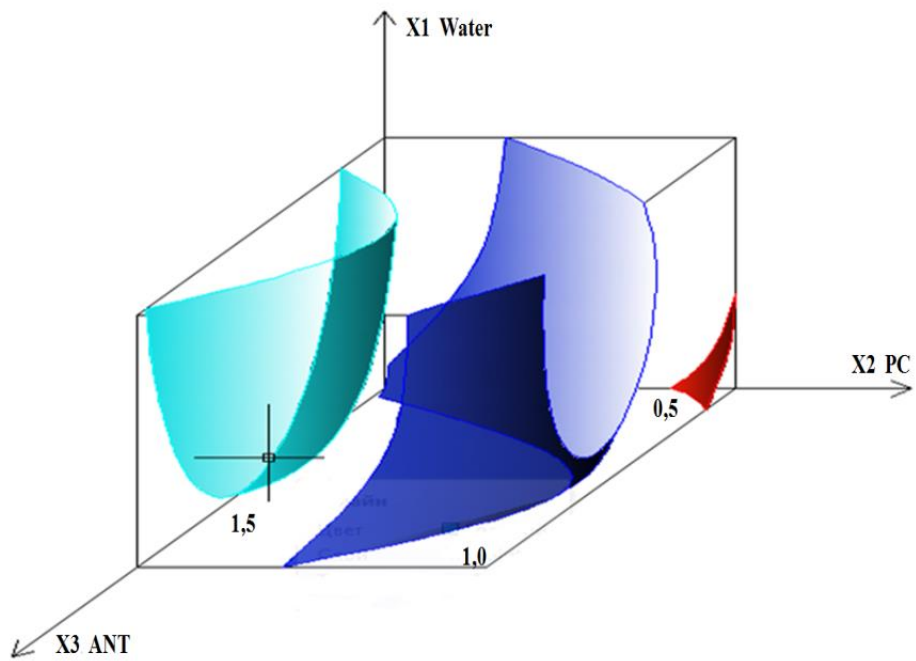

Fig. 2. Isosurfaces of tensile strength in bending 


\section{Conclusions}

The results of the complete three-factor experiment led to the following conclusions on the examination of the effect of the variates (content of mixing water, mineral binder and ANT ionic stabilizer) on the physical-mechanical properties of stabilized macadam and sand mixes (MSM).

During transition from +1 to -1 variate $X_{1}$ exerts almost no influence on the properties of stabilized macadam and sand mixes under study. That is why increase in the mixing water content higher than the central values of the variability interval $\mathrm{X}_{1}>0$ is inadvisable.

Within the variability interval $\mathrm{X}_{2}$ from -1 to +1 there is observed a considerable increase in the strength property of the material (Fig.1, Table 3). However with the increase in the portland cement concentration there was identified a decrease in the fatigue strength criterion Rbend/Rcompr (Figure 2, Table 3). Strength and stress-strain properties of stabilized MSM's are characterized mostly by the structure and properties of the cement stone which solidifies the filler grains. Development of crystallizing bonds boosts mechanical strength; however fragile properties begin to appear which reduce cracking resistance of stabilized MSM's. That is why increase in the mineral binder content higher than the central values of the variability interval $X_{2}>0$ is inadvisable.

During introduction of additives it is possible to significantly change the strength and stress-strain properties of stabilized MSM's. Increase in the compression strength during modification with the ANT stabilizer is explained by appearance of the adsorption bed on the surface of cement grains [20].

The principal factor exerting influence on strength property of stabilized macadam and sand mixes is application of the ANT $\mathrm{X}_{3}$ ionic stabilizer, enabling changing of strength from 3.00 to $5.24 \mathrm{MPa}$. At the same time, as it follows from Fig. 1, even with the minimum quantity of the binder ( $2 \%$ ) the ANT stabilizer increases the compression strength. With the maximum quantity of the binder (4\%) there has also been observed an increase in the compression strength, but along with this there has been observed a decrease in the fatigue strength criterion Rbend/Rcompr and weakening of the material's cracking resistance. It is primarily associated with the excess quantity of crystallizing contacts or bonds in the material's structure. The optimal content of the binder $(3 \%)$ and the range of application of the ANT ionic stabilizer $(0.3 \%)$ enable obtaining of the best possible effect of the physicalmechanical and stress-strain properties of materials. It follows from the above that the compression strength and the tensile strength in bending of the samples prepared from stabilized macadam and sand mixes together with the ANT ionic stabilizer is 20 to $25 \%$ higher than the strength of conventional stabilized MSM's without additives. Another criterion recorded basing upon the results of the experiments was the fatigue strength Rbend/Rcompr criterion which constitutes 0.17 for the samples of cement-stabilized MSM's. At introduction of the ANT additive to the stabilized material this index rises up to 0.21 or by $20 \%$. Increase of the Rbend/Rcompr ratio is the evidence of the mix's lower tendency to cracking [21], which is a rather important factor during construction of base courses with mineral binder-stabilized materials.

\section{References}

1. V. A. Voznesensky, Modern Methods of Composite Materials Optimization 144 (1983)

2. V.A. Voznesensky, Numerical Methods of Computer-Aided Solution of Construction Technology Problems 328 (1989)

3. V.S. Izotov, Yu. A. Sokolova, Chemical Additives for Concrete Modification 244 (2006)

4. I. Maiti, Ciba-Geigi AG Japanese Company’s Corporate Information 5 (1977) 
5. Melment Application in Concrete Southern German Plants Company's Corporate Information 31 (1977)

6. V. Adam, M. Hovorka, I. Tomanek, A. Stipeks Yyuziti plastifikatori Sillix v zavode Malesice 2, 71 (1978)

7. E. Şevki, F. Mümin Beyaz Bentonit Malzemesinde Alternatif Katkı Maddesi Olarak Kullanılan Consolid Sistemi ile Geleneksel Zemin Stabilizasyon Yöntemlerinin Karşılaştırılması 11-2, 163 (2007)

8. N. Holmes Structural Properties of Concrete Materials Containing RoadCem 8 (2015)

9. P. Wu Cement-bound road base materials. Delft University of Technology 218 (2011)

10. P. Sherwood Soil Stabilization with Cement and Lime, HMSO (1993)

11. D. J. Maclean, P. J. M. Robinson, S. B. Webb An investigation of the stabilization of heavy clay soil with cement for road base construction, 358, 287 (1952)

12. M. S. Kersten Soil Stabilization with Portland Cement. National Academy of Sciences National Research Council (1961)

13. Unified Facilities Criteria, Soil Stabilization for Pavements, United States Army Corps of Engineers (2004)

14. D. N. Little Handbook for Stabilization of Pavement Subgrades and Base Courses with Lime (1995)

15. K. Newman, J.S. Tingle Emulsion polymers for soil stabilization (2004)

16. Technical Specifications: Warm Recycling of Asphalt Concretes with Application of the "ANT Soils and Organo-Mineral Mixes Stabilizer"20 (2011)

17. S.G. Fursov Construction of Pavement Layers out of Binder-Stabilized Soils, 3, 21 (2007)

18. V.P. Matua, S.V. Sizonets, R.V. Matua Science and Engineering in Highway Engineering, 4, 16 (2012)

19. V.P. Matua, S.V. Sizonets, R.V. Matua New Technologies, 1, 55 (2013)

20. Yu. M. Bazhenov Concrete Technology 500 (2002)

21. D. Schumann Putz fur Bauwerke Arbeite 22, 34 (1981) 